\title{
Successful Pregnancy after Previous Uterine Rupture
}

*Kenusha Devi Tiwari, Aruna Karki, Ganesh Dangal, Hema Pradhan, Ranjana Shrestha, Kabin Bhattachan, Rekha Poudel, Nishma Bajracharya, Sonu Bharati

\section{Author(s) Affiliation:}

Department of Obstetrics and Gynecology, Kathmandu Model Hospital, Nepal

\section{*Corresponding Author:}

Dr. Kenusha Devi Tiwari

FCPS Resident in Obstetrics and Gynaecology

Department of Obstetrics and Gynaecology

Kathmandu Model Hospital,

Kathmandu, Nepal

Email/Contact:

kenushadevitiwari@gmail.com +977-9860-937294

\begin{abstract}
Uterine rupture is a rare and catastrophic incidence with high maternal and fetal morbidity rates. It is most commonly seen in the scarred uterus. The unscarred uterus is least susceptible to rupture with the incidence being 1 in 8000 deliveries. In the past, pregnancy after uterine rupture was not widely advised and patients underwent hysterectomy or tubal ligation but with the evolving practice, women are motivated for pregnancy which can be successful with proper obstetric care and emphasis on time and mode of delivery. Here we present a case of 31 years old female, gravida 2 para 1 living 0 with previous uterine rupture after medical induction of labor with stillbirth 4 years ago. She underwent emergency laparotomy with the repair. The patient spontaneously conceived and had close antenatal care throughout the pregnancy. The patient was admitted at 34 weeks of gestation and kept under close surveillance. Corticosteroid was administered. She underwent spontaneous labor at 37 weeks of gestation and emergency cesarean section was planned, delivered via a breech presentation to a live baby of $2.4 \mathrm{~kg}$, APGAR score of $8 / 10,9 / 10$ at 1 and 5 minutes.
\end{abstract}

Keywords: cesarean delivery, pregnancy, uterine rupture

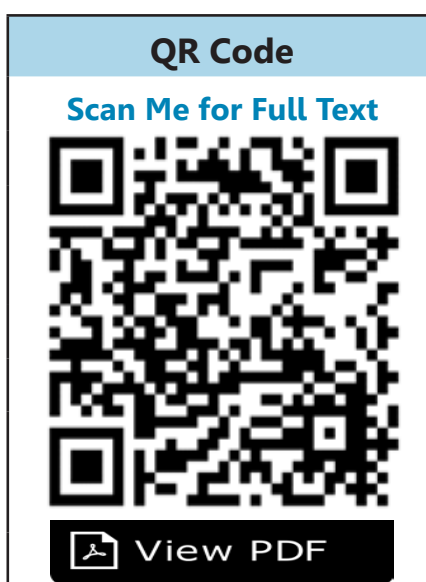

\section{Article Info}

Received: 14 December 2019; Accepted: 1 March 2020; Published Online: 3 March 2020

How to cite this article in Vancouver Style?

Tiwari KD, Karki A, Dangal G, Pradhan H, Shrestha S, Bhattachan B, Poudel P, Bajracharya N, Bharati S. Successful Pregnancy after Previous Uterine Rupture.Europasian J Med Sci. 2020;2(1):99-102. https://doi.org/10.46405/ejms.v2i1.22

Conflict of Interest: None Declared;

Source of Support: Nil

Copyright: (c) 2020 by author(s). This is an open access article distributed under the terms of the Creative Commons Attribution International License 4.0 @- (9) which permits unrestricted use, distribution, and reproduction in any medium, provided the original work is properly cited.

\section{Publisher's Note}

The Europasian Journal of Medical Sciences (EJMS) is an official Journal of Nirvana Psychosocial Care Center \& Research Institute (www. nirvanapscc.com) and published by it. The Journal as well as publisher remain neutral with regards to any jurisdictional claims in any published articles, its contents and the institutional affiliations of the author(s). 


\section{INTRODUCTION}

Uterine rupture is a formidable incidence with the potentially life-threatening and devastating condition. It is considered to be one of the serious obstetric emergency. Uterine rupture typically is classified as complete when all layers of the uterine wall are separated and incomplete when the muscle is separated but visceral peritoneum is intact also referred to as dehiscence. Morbidity and mortality are greater with complete rupture. Although it most frequently occurs during labor, it can occur before labor as well. The greatest risk factor for uterine rupture is scarred uterus.

The rupture of an unscarred uterus is reported to occur at a rate of 1 in 8000 deliveries. ${ }^{1}$ For women with a history of a uterine rupture, the recurrence risk of uterine rupture ranges in the literature from $4 \%$ to $33 \% .^{1}$ In women undergoing a trial of labor after cesarean section is $0.2 \%-1 \%{ }^{2}$ National data on the incidence of uterine rupture has not been recorded but, in a study conducted by Uprety I et al in tertiary central hospital of Nepal, Paropakar Maternity Women's Hospital, 1 rupture in 1390 pregnancies was noted with $1.5 \%$ in the scarred uterus and $0.64 \%$ in the unscarred uterus. Scarred uterine rupture was secondary to the previous cesarean section in labor. ${ }^{3}$ Due to poor neonatal prognosis, parents often express their desire of having a new child. However, data about the outcome of subsequent pregnancies after a rupture are sparse and discordant and are limited to case reports and case series only. Here we present a case of 31 years old patients who had a successful pregnancy after a spontaneous uterine rupture in a previous pregnancy.

\section{CASE PRESENTATION}

A 31 years old female Gravida 2 Para 1 Living 0 was admitted to our institution at 34 weeks of gestation with a history of previous uterine rupture 4 years ago. Four years ago the patient was admitted at 41 weeks 2 days of gestation for induction of labor. She was inducted medically with misoprostol $25 \mathrm{mcg}$ per vagina 4 hourly for 3 doses. Labor was augmented with $2.5 \mathrm{U}$ oxytocin 6 hours after the last dose of misoprostol. She developed moderate contraction until she started having severe abdominal pain with a sudden drop in blood pressure and uterine rupture was suspected and emergency laparotomy was done. Complete rupture at the lower uterine segment extending laterally up to fundus at the left side was noted. The fetus was partially extruded was in the abdominal cavity with fresh stillbirth. $300 \mathrm{ml}$ of retro placental clots retrieved. The primary closure of the uterus was done. The patient was monitored postoperatively and discharged. She conceived spontaneously after 4 years. With reassurance, the patient was advised to continue the pregnancy and was on regular follow up. The patient was admitted at 34 weeks of gestation onwards for observation. Dexamethasone 12mg IM 2 doses 12 hours apart given for lung maturity of fetus. At 37 weeks of gestation, the patient went into labor and an emergency cesarean section was done. Low uterine incision was given and $2 \mathrm{~kg}$ baby was delivered via breech presentation with APGAR score of 8/10, $9 / 10$ at 1 and 5 minutes. The left lateral previous scar was intact and thick. Intra-operative and postoperative period was uneventful. The patient was discharged on $3^{\text {rd }}$ post-operative day. Upon follow up at 1 week, both patient and baby were healthy.

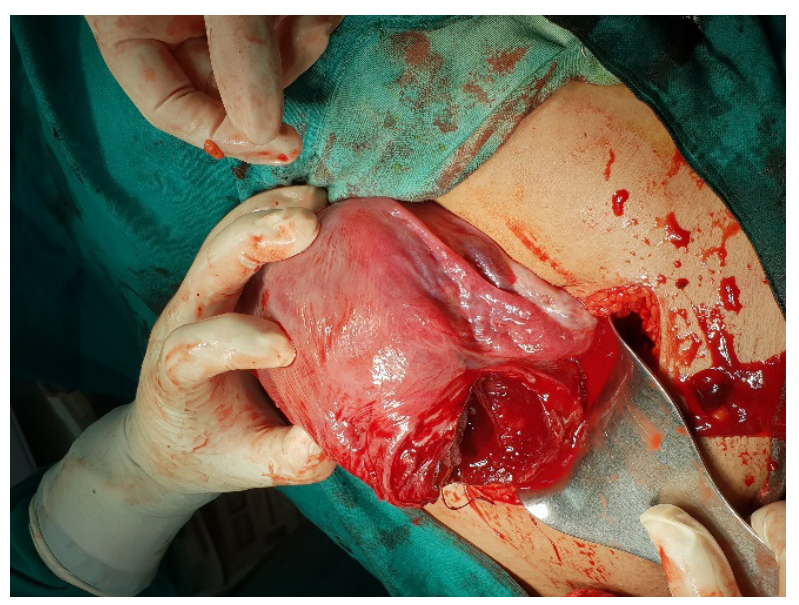

Figure 1: Photograph showing the procedure of cesarean section for the rupture Uterus

\section{DISCUSSION}

Uterine rupture, if not detected timely and if no timely intervention is done, has a disastrous outcome on both maternal and fetal mortality. The most common risk factors for uterine rupture are previous uterine rupture, previous cesarean delivery, grand multiparity, uterine anomaly, fetal malpresentation, fetal macrosomia, induced labor, obstructed labor or instrumental delivery. ${ }^{3}$ Like in our case, the patient had rupture after induction of labor. These risk factors contributed to $84 \%$ of uterine ruptures in a study conducted by Uprety et al. ${ }^{3}$ Induction or augmentation of labor with oxytocin has been implicated in increased rates of uterine rupture. Uterine rupture was more frequent in women induced $1.1 \%$ than spontaneous labor of $0.4 \%$. Diagnosis can be non-specific. The most common sign of uterine rupture is non-reassuring fetal heart pattern with variable heart rate decelerations that may evolve into late decelerations and bradycardia with sudden hypovolemic shock. With rupture and expulsion of the fetus into the peritoneal cavity, the chances for intact 
fetal survival are $50-75 \%$. Fetal condition is dependent on which the placental implantation remains intact. Severe neurological morbidity is seen in the surviving fetus. ${ }^{4}$ In our case fetus was partially excluded into the abdominal cavity with fresh stillbirth.

In the past, it was commonly advised that either hysterectomy or, sterilization be performed in the treatment of uterine rupture to prevent recurrent ruptures in a future pregnancy. In 1969, Reyes-Ceja et al published a case series of 22 pregnancies among 19 women with prior rupture from a single institution in Mexico. Repeat rupture occurred in only one patient leading the authors to conclude that surgical repair of the ruptured uterus instead of hysterectomy has a place in obstetric practice. ${ }^{5}$ The decision of repair is mainly based on the extent, type and location of the rupture and hemodynamic status of the patient. Hysterectomy in the case of uterine rupture is today performed in $4 \%$ to $10 \%{ }^{6}$ In the study by Uprety I et al, subtotal hysterectomy was done in $14 \%$ cases $(n=28)$ and tubal ligation was done in $14 \%$ cases who underwent repair. ${ }^{3}$ Singh et al. have also concluded in her study that $25 \%$ of peripartum hysterectomy was secondary to uterine rupture. ${ }^{7}$ In a study conducted by Chibber $\mathrm{R}$ et al., ${ }^{8}$ of 44 pregnancies $45 \%$ had an abdominal hysterectomy, the remaining 10 had suture repair with 2 sterilization and rest 14 underwent suture repair with hypogastric artery ligation to control bleeding and reproductive function. Our patient had primary suture repair and sterilization was not done as patient and family members were hopeful for the next pregnancy.

Ideal management strategy for uterine rupture and pregnancy after the uterine rupture has not been developed due to limitations to case reports and case series. Obstetricians are left to their best clinical judgment in managing these patients. The published reports over the last 100 years indicate that most women with previous uterine rupture have a favorable outcome in subsequent pregnancies. In a study by Usta et al. $^{9}$ of 24 pregnancies with prior uterine rupture, a $33 \%$ risk of recurrent uterine rupture was recorded. Similarly, Shick $\mathrm{S}$ et al. $^{10}$ reported the outcome of 13 pregnancies with prior rupture, 3 patients (23\%) had recurrent rupture They concluded that the risk of rupture was high in previous longitudinal rupture and when the interval between subsequent pregnancy was shorter, in their case 2 versus 5 years. Delecour L et al. ${ }^{11}$ studied 11 pregnancies after rupture and the median interval between pregnancy was 24 months. In a study conducted by Chibber $R$ et al. ${ }^{8}$ of 24 successful pregnancies after rupture, 2 mortalities were recorded secondary to the ruptured uterus and they were the ones noted to have a sparse antenatal checkup. Surprisingly, in contrast to this, Fox NS et $\mathrm{al}^{1}$ out of 20 pregnancies following uterine rupture, there was no recurrence of uterine rupture with $100 \%$ successful pregnancy and no neonatal morbidity. 5.0\% $(95 \% \mathrm{Cl}$ 0.9-23.6\%) women with prior rupture had uterine dehiscence. Besides, in a review conducted by Larrea et $\mathrm{al}^{5}$ the reported rate of repeat rupture ranges from $4 \%-32 \%$ and with higher qualities modern studies and close follow up risk has decreased to $4 \%-15 \%$, on the greater side with the history of upper uterine segment rupture.

Other severe morbidities associated are bladder injury, bowel injury, mechanical ventilation, intensive care unit admission, thrombosis, reoperation, maternal death, and perinatal death, placenta previa, placenta accrete, uterine dehiscence at delivery are encountered sparsely. ${ }^{1,12}$ However, no such morbidities were encountered in our case.

In a case series by Fox NS et $\mathrm{al}^{1}$ and Delecour et al. ${ }^{11}$ patients were attributed to serial ultrasounds every month to asses fetal growth and lower uterine integrity and placental growth. The optimal cut off value varied from $2.0 \mathrm{~mm}$ to $3.5 \mathrm{~mm}$ for the full lower uterine segment thickness, and $1.4 \mathrm{~mm}$ to $2.0 \mathrm{~mm}$ for the myometrial layer. However, the findings like uterine dehiscence in an earlier gestational period did not change the clinical decision making in delivery time. Rather, patients were admitted for observation and waited for an elective cesarean at 36-37 weeks of gestation or earlier if needed or else before the onset of labor. Standardization and validation are still required before implementing the use of ultrasound for scar assessment. ${ }^{13}$ Our patient was not attributed to monthly ultrasound, however, scar assessment was done at 30 weeks of gestation and found it to be 2 $\mathrm{mm}$.

Based on different studies, the cesarean section must be planned between 36-38 weeks of gestation. ${ }^{1,5,8,9,11}$ This is guided by the location of the previous scar and timing of rupture as well. Those with ruptured lower uterine scar delivery at 37-38 weeks of gestation is recommended. Similarly, for upper uterine rupture opinion varies. Some advised delivery at 35 weeks of gestation and some have advised early admission at 34-35 weeks of gestation or hospital 1 week before the gestational age at which labor stated in the previous pregnancy. Chibber et al. ${ }^{8}$ had 16 with low transverse scar delivered at 37 weeks and 4 pregnancies at 35 weeks due to upper uterine rupture scar. If delivery is planned before 37 weeks, amniocentesis for fetal lung maturity can be done. Like in our case we decided to admit the patient at 34 weeks of gestation onwards for observation. Corticosteroid was administered and wait, watch protocol followed. Fox NS et al. ${ }^{1}$ did it in $51 \%$ cases. The administration of antenatal late preterm steroids should be considered to reduce the risk of neonatal respiratory morbidity 


\section{CONCLUSION}

Pregnancy after uterine rupture can be successful, given that proper obstetric care is provided with the main focus on time and mode of delivery i.e standardized approach with planned cesarean delivery before labor onset results in good outcomes. The location of the previous scar and timing of rupture should also be reflected upon. If delivery is planned before 37 weeks of gestation, the administration of corticosteroids must be considered to reduce the risk of neonatal respiratory morbidity. Patient education and awareness about risk or recurrence of uterine rupture or dehiscence with signs of labor are instructed to seek medical help immediately.

\section{REFERENCES}

1.Fox NS, Gerber RS, Mourad M, Saltzman DH, Klauser CK, Gupta S et al. Pregnancy outcomes in patients with prior uterine rupture or dehiscence. Obset \& Gynecol. 2014;123(4):785-9. https://doi. org/10.1097/AOG.0000000000000181

\section{GoogleScholar | CrossRef | PubMed | Full Text}

2. Motomura K, Ganchimeg T, Nagata C, Ota E, Vogel JP, Betran AP,et al. Incidence and outcomes of uterine rupture among women with prior caesarean section: WHO Multicountry Survey on Maternal and Newborn Health. Scientific reports. 2017;7:44093. https://doi.org/10.1038/ srep44093 Google Scholar CrossRef PubMed Full Text

3.Uprety I, Baral G, Shrestha S. Review of uterine rupture at Paropakar Maternity and Women's Hospital. NJOG. 2018;13(1):23-5. https://doi. org/10.3126/njog.v13i1.21612

\section{Google Scholar CrossRef Full Text}

4. Cunningham, F. G., Leveno, K. J., Bloom, S. L., Spong, C. Y., Dashe, J. S., Hoffman, B. L et al. (2014). Williams obstetrics.24th edition. New York: McGraw-Hill Education

Google Scholar | Full Text

5.Larrea NA, Metz TD. Pregnancy After Uterine Rupture. Obstet Gynecol. 2018;131(1):135-7. $\quad$ https://doi.org/10.1097/ AOG.0000000000002373

Google Scholar CrossRef PubMed Full Text
6.Lim AC, Kwee A, Bruinse HW. Pregnancy after uterine rupture: a report of 5 cases and a review of the literature. Obstet Gynecol surv. 2005;60(9):613-7. https://doi.org/10.1097/01. ogx.0000176677.26657.6c

Google Scholar CrossRef PubMed Full Text

7.Singh A, Hada M, Yangzom K, Anita GC. Emergency peripartum hysterectomy. NJOG. 2006;1(2):33-6. https://doi.org/10.3126/njog. v1i2.2395

Google Scholar CrossRef Full Text

8.Chibber R, El-Saleh E, Fadhli RA, JassarWA, Harmi $J A$. Uterine rupture and subsequent pregnancy outcome-how safe is it? A 25-year study. J Matern Fetal Neonatal Med.2010;23(5):421-4. https://doi.org/10.3109/14767050903440489 Google Scholar CrossRef PubMed Full Text

9.Usta IM, Hamdi MA, Musa AA, Nassar $\mathrm{AH}$. Pregnancy outcome in patients with previous uterine rupture. Acta Obstet Gynecol Scand.2007;86(2):172-6. https://doi. org/10.1080/00016340601089768

Google Scholar CrossRef PubMed Full Text

10.Shick S, Neiger R. Pregnancy outcome in women with history of uterine rupture or dehiscence. Obstet Gynecol cases Rev.2015;2:5. https://doi.org/10.23937/2377-9004/1410052

\section{Google Scholar CrossRef Full Text}

11.Delecour L, Rudigoz RC, Dubernard G, Huissoud C. Pregnancy and delivery after complete uterine rupture. J Gynecol Obstet Hum Reprod.2018;47(1):23-8. https://doi. org/10.1016/j.jogoh.2017.10.004

\section{Google Scholar CrossRef PubMed Full Text}

12.Revicky V, Muralidhar A, Mukhopadhyay S, Mahmood T. A case series of uterine rupture: lessons to be learned for future clinical practice. J Obstet Gynaecol India.2012;62(6):665-73. https://doi.org/10.1007/s13224-012-0328-4

Google Scholar CrossRef PubMed Full Text

13. Spong CY, Queenan JT. Uterine scar assessment: how should it be done before trial of labor after cesarean delivery?. Obstet Gynecol.2011;117(3):521-2.

org/10.1097/AOG.0b013e31820ce593

Google Scholar CrossRef PubMed Full Text 